\title{
Knowledge Acquisition Using Group Support Systems
}

\author{
Igor Pyrko ${ }^{1} \cdot$ Colin Eden $^{2} \cdot$ Susan Howick ${ }^{2}$
}

Published online: 18 February 2019

(c) The Author(s) 2019

\begin{abstract}
This paper reports on a project in which a group support system (GSS) equipped with a causal mapping facility was used to acquire knowledge from experts in seven European cities in order to understand the systemicity of risks which cities may face. The practical constraints demanded that participants' experience and wisdom about the city risk environment was collected in a short period of time: three 1-day workshops. The acquisition of knowledge posed a number of important epistemological challenges which are explored in our discussion. The GSS was faced with the need to (1) facilitate sharing of knowledge with others, (2) manage the complexity of expert knowledge, (3) acknowledge the time demands on experts, (4) manage and merge multiple perspectives, and (5) acknowledge the subjectivity of knowledge in this domain. By discussing how the GSS process attended directly to these epistemological issues and to methodological considerations that linked to these issues, the paper contributes to a better understanding of the application of GSS for knowledge acquisition, particularly in comparison with other possible methods.
\end{abstract}

Keywords Knowledge acquisition · Causal mapping · Group support systems · Tacit knowledge $\cdot$ Resilience

\footnotetext{
$\bowtie \quad$ Igor Pyrko

i.pyrko@aston.ac.uk

Colin Eden

colin.eden@strath.ac.uk

Susan Howick

susan.howick@strath.ac.uk

1 Marketing and Strategy Department, Aston University, Aston Triangle, Birmingham B4 7ET, UK

2 Department of Management Science, University of Strathclyde, 130 Rottenrow, Glasgow G4 0GE, UK
} 


\section{Introduction}

In many situations, building decision support tools requires acquiring a large amount of expert knowledge. However, acquiring expert knowledge for this purpose can be problematic for a number of reasons. Firstly, experts are valuable because they have expert knowledge and are reticent to give it away. Secondly, expert knowledge is usually complex and so cannot be captured without a recognition of its context. Thirdly, experts' time is valuable and so they are usually unable to devote much time to the knowledge acquisition process. Fourthly, relevant knowledge often lies across many experts and so must be merged for it to be of most use. Fifthly, knowledge can be highly subjective and debatable across multiple experts. We discuss each of these issues in turn and their implications for designing an effective and practical knowledge acquisition process.

In this reported research a group support system (GSS) (Lewis 2010) was applied to acquire knowledge from groups of experts from seven European cities who were interested in improving their cities' resilience through a better appreciation of risk. GSSs have been used to facilitate sessions in which groups negotiate an agreed strategy (Ackermann and Eden 2011; Eden and Ackermann 2000; Paroutis et al. 2015), risk management (Ackermann et al. 2007, 2014), problem structuring (Eden 2004), or project management (Ackermann and Eden 2005). GSS's have also been used extensively in brain-storming (Nunamaker et al. 1991) and in decision making where multiple criteria were a major factor (Lewis 1993). In a typical GSS-facilitated session, participants from the same organization address a specific set of problems relevant to their work, and by pooling their expertise they co-create new options to address those problems. Thus, the focal points of the session become the solutions which participants should ideally feel ownership of, and agree to act upon, in order to change their projects or organizations for the better (Tavella and Franco 2015).

In this paper, we present a non-traditional approach for using GSS in a group meeting where expert views were gathered from participants from multiple organizations with the aim of acquiring vast expert knowledge in a relatively short time period, instead of focusing on finding a solution to a problem or building ownership of the problem. Unlike previous applications of GSS for knowledge acquisition (Liou and Nunamaker 1990), our purpose was not to build a knowledge base for an expert system, but rather to develop an understanding of the interaction between risks and so inform the construction of a decision support tool aimed at operationalizing city resilience. This novel application of GSS, in turn, brings new epistemological and methodological considerations that we address in our discussion. This paper extends and elaborates a paper presented at the 2017 GDN conference and which was published in the conference proceedings (Eden et al. 2017).

The notion of knowledge creation and acquisition is described in the popular model by Nonaka and Takeuchi (1995). This model represents the conversion between tacit and explicit knowledge (and vice versa). This 'knowledge conversion spiral' contains the conversion from explicit to tacit through internalization, from tacit to tacit through socialization, from tacit to explicit through externalization and from explicit to explicit through combination. The particularly important aspect of this model for our argument is externalization because we investigate how city experts' deep, tacit knowledge can 
be converted into explicit form with the aid of a GSS as part of a facilitated process of discussing risk scenarios.

However, we concurrently note the criticism of Nonaka and Takeuchi's model discussed in the management literature (Dörfler 2010; Snowden 2003; Thompson and Walsham 2004; Tsoukas 2005). These authors argue that tacit knowledge should be understood more as a dimension of knowledge rather than a distinct type of knowledge, which means that tacit knowledge cannot be converted literally into tacit form because tacit knowledge is too rich to be fully externalized. In other words, tacit knowledge can be seen as 'the bottom of an iceberg' which underpins all knowledge (as discussed in Polanyi 1966a). This means that acquisition of expert knowledge using GSS is inevitably highly problematic and it poses a number of epistemological challenges which we focus on in our discussion. In addition, from the methodological perspective, knowledge acquisition calls for a process which accounts for the social and contextsensitive nature of knowledge - and therefore the possibility of facilitating such a process is an important consideration in this paper.

The structure of this paper is as follows. We first discuss knowledge acquisition as a social process, and we consider five epistemological challenges which it entails. We then go on to debate the different methodologies which can be applied to resolve the epistemological challenges in knowledge acquisition, and we conclude that using a GSS can be a particularly good way of dealing with those challenges. We subsequently introduce a research project where a GSS was used to gather experts views from participants from multiple organizations with respect to future risk scenarios that a city might face. These risk scenarios were then used to build a resilience-oriented decision support tool. In the last two sections of the paper, we consider some of the significant issues and debates with gaining expert knowledge that emerged when developing a decision support tool, how a GSS can deal with these and how they link to the five epistemological challenges. We also reflect on some of the trade-offs that are made when using a GSS compared to other methods of knowledge acquisition.

\section{Epistemological Challenges in Knowledge Acquisition}

In this section we present five epistemological challenges which need to be addressed when attempting to acquire expert knowledge. These challenges are based on the existing literature which deals with knowledge management in organizations. The appreciation of these epistemological challenges provides a foundation for our subsequent discussion in which we consider the methodological requirements to address these challenges. This in turn implies that the application of a GSS is particularly well suited to the acquisition of expert knowledge in a relatively short time period.

\subsection{Sharing Expert Knowledge with Others}

The first epistemological challenge involved in knowledge acquisition follows from expert knowledge being of value and so those with such knowledge will be reticent to give it away. Experts value and 'defend' their knowledge because it is the main 
source of their power in organizations (Davenport 2005; Davenport and Prusak 2000). In addition, in today's fast-paced job markets, experts tend to be more loyal to their expert knowledge and to their sense of professional identity rather than to their organizational allegiance (Handy 1995, 2016). Success in competitive environments relies on knowledge, and how knowledge is applied to strategy and business processes (Donate and Canales 2012; Drucker and Maciariello 2008; Wenger 2000). At the same time, using knowledge to keep an organization competitive is crucial (Barney 1991) but challenging for sustaining competitiveness (Starbuck 1992).

Whilst experts may be reluctant to share knowledge, it has been recognized that they are more likely to share knowledge when they are members of self-governed social structures called Communities of Practice (CoPs) (Borzillo and KaminskaLabbé 2011; Borzillo et al. 2012). Such communities are groups of people who learn from one another regularly and thereby share deep, tacit knowledge (Wenger et al. 2002). CoPs tend to originate as practitioners think together about real-life problems which they mutually face (Pyrko et al. 2017a). However, cultivation of CoPs is not easy as it requires a delicate balancing between giving CoP members enough autonomy whilst assigning them with formal tasks that justify investing in them as organizational resources (McDermott and Archibald 2010; Wenger and Snyder 2000). In addition, in busy professional settings there may not always be space for sustained professional relationships that are essential for lively CoPs (Roberts 2006). Therefore, looser and more temporal social structures than CoPs (Brown and Duguid 2000) such as collectivities of practice may in some cases be more feasible to develop in organizations (Lindkvist 2005). However, even collectivities of practice require opportunities to attend to the same real-life problems within the organizational context which may require facilitation with appropriate tools and techniques. The participants (experts) in this research became an example of a self-governed social structure in which participants from different cities were identifying one another as learning partners. They did so by contributing together to workshops and by collaborating on project outputs such as deliverables. Whilst their interactions were too irregular to be seen as a $\mathrm{CoP}$ (the participants would meet every couple of months and they hosted occasional videoconferences in-between the project events), they could be seen as a less intensive collectivity of practice in which informal learning across city teams took place.

\subsection{Complexity of Knowledge}

The second epistemological challenge in knowledge acquisition is that knowledge is usually complex and so cannot be captured without a recognition of its context. Tsoukas and Vladimirou (2001) define knowledge as “... the individual ability to draw distinctions within a collective domain of action, based on an appreciation of context or theory, or both". This means that knowledge is context-sensitive as people become competent in using what they know under particular circumstances, such as a junior surgeon learning how to perform their practice in the surgery theatre. 'Theory' is understood here in broad terms, referring to abstract principles guiding one's performance in practice, for example a lawyer applying legal terms in the courtroom. Tsoukas and Vladmirou draw heavily on Polanyi (1962) who portrays knowledge as 
being inherently personal and underpinned by the tacit component. Since the idea of a tacit component entails that tacit knowledge underpins all knowledge, hence "a wholly explicit knowledge is unthinkable" (Polanyi 1966a).

Therefore, while to some extent it is useful to draw on Nonaka and Takeuchi's (1995) process of externalization, that is conversion of tacit knowledge to explicit knowledge, as the objective of knowledge acquisition, we note the limitations of this work. Considering that most peoples' knowledge is inherently tacit (Polanyi 1962), by 'knowledge acquisition' we do not imply accessing the whole of a person's knowledge about a subject of reference, neither do we attempt to measure their knowledge - in other words, tacit knowledge cannot be literally converted into an explicit form. Instead, we can only represent some relevant and important aspects of peoples' thoughts about a given question or problem (Eden 1992a) and such endeavor can be particularly fruitful if one is able to map out the causality between the constructs in a person's understanding of the problem (Eden et al. 1981). By mapping problems visually a group can contextualize their knowledge (with the context being a system of causal relationships) which serves a better understanding of these problems between the individuals.

\subsection{Time Demands}

The third epistemological challenge in knowledge acquisition is that experts' time is valuable and so they are usually unable to devote much time to the knowledge acquisition process. There are many ways to acquire and share knowledge in a workplace, but to be able to succeed with any form of knowledge management, companies have to understand the importance of committing enough time and resources to learning and knowledge sharing (Walz et al. 1993; Wickert and Herschel 2001). Simply deploying technology does not guarantee successful outcomes with respect to knowledge management (McDermott 1999). Therefore, when working with experts, it is essential to introduce a process that involves (1) high productivity and (2) ability to interact and work together in real-time. The reason for the former is that high productivity enables good outcomes within a limited amount of time, and so it is possible to make most of the experts' availability. The justification for the latter is, in turn, that experts can mutually negotiate the given problems 'on the hoof' and so achieve a shared understanding during the limited time demands of the meeting. The use of a GSS for knowledge acquisition therefore needs to be able to meet these two requirements.

\subsection{Merging Multiple Perspectives}

The fourth epistemological challenge is that the knowledge required often lies across many experts and so must be merged for it to be of most use. Effective knowledge acquisition seeks to capture different expertise from many experts and combine this so that the new knowledge is created through the process of sharing multiple perspectives. The process of knowledge acquisition should, ideally, facilitate the merging and linking of knowledge in the group process so that the group can explore and develop new knowledge (Ackermann et al. 2016; Eden et al. 1981; Spender 1996; Tsoukas 1996). Along these lines, knowledge can be highly subjective and debatable across 
multiple experts. It may therefore be important to visually map the intersubjectvity of experts and so can recognize conflict as well as commonalities in understandings (Eden et al. 1981). A proven technique for mapping intersubjectvity is a causal mapping technique (Ackermann et al. 2005; Bryson et al. 2004; Shaw et al. 2017). A causal map serves as a 'boundary object' for group completion —an object that is “... shared and shareable across different problem solving contexts" (Carlile 2002, 2004). In addition, a causal map can be seen as a transitional object, that is an object which is modified by participants and which therefore changes along with the alterations in participants' understanding of the discussed problems (de Geus 1988). As a result, the causal map, serving the role of a boundary object and a transitionary object, helps to capture the multiple perspectives of different experts.

\subsection{Subjectivity of Knowledge}

The fifth challenge for knowledge acquisition is that knowledge is, as outlined by personal construct psychology, inherently subjective. Kelly (1955) provides a body of theory that suggests people make sense of their world(s) through anticipation as they seek to act. The act of construal is important in contrast to a focus on perception-it is construal that facilitates sense making. Thus, knowledge is related to the process of giving meaning rather than to simply information (as also discussed in Gherardi 2000; Polanyi 1967). In knowledge acquisition it is therefore important to capture causality - the consequences of knowing and the explanation for knowing in order to acquire knowledge as meaning. In other words, instead of merely capturing information, the goal of knowledge acquisition should be to understand the context that is the meaning. One approach for capturing meaning this way is the causal mapping technique mentioned above, and this helps to explain why a GSS equipped with a casual mapping facility was selected for this research.

\section{Group Support System as a Methodology for Knowledge Acquisition}

In the project reported in this paper all of the five identified epistemological challenges were relevant. The task was to collect expert views about future risk scenarios that a city might face and which could be used in a tool designed to help cities use the expert knowledge to undertake effective risk assessment. Access to experts was restricted to 3 separate days ( 3 workshops) and was to involve experts from a range of European cities.

With respect to the five epistemological challenges identified above, the following project-specific considerations had to be taken into account:

- As none of the experts had previously worked together, the process had to engage them and encourage them to share their knowledge.

- The complexity of risk scenarios within cities meant that the context of the experts' knowledge that surrounds the scenarios needed to be understood. 
- The restrictive availability of the experts meant there was significant time demands and effective use of the experts' time was paramount.

- Knowledge from a number of European cities and a range of areas covering critical infrastructure, climate change and social dynamics meant that a wide range of perspectives needed to be considered.

- As future risk scenarios were of interest, the knowledge that would be captured was subjective and the process needed to allow for debate amongst the experts and an approach to resolve any conflicts and develop jointly created meanings.

Thus, any methodological approach used to acquire knowledge needed to take account of each of these project-specific considerations. Possible and obvious ways to acquire such knowledge were considered as follows:

Interviews: interviews can be an efficient way in which to engage participants as their involvement can be kept to a minimum as researchers can focus on only gathering their knowledge (Alvesson 2011; Dundon and Ryan 2010). However, the limitation of this method is that there is no ability to use process as a way of getting at tacit knowledge. Moreover, participants are likely to be scared of exposing ignorance and so making up a view (Easterby-Smith et al. 2015). In addition, differences in multiple perspectives could not easily be considered between participants and thus allow for debate between participants.

Questionnaires: with respect to questionnaires there are similar pros and cons to using interviews, however, a questionnaire is more restrictive for the researchers as there is no scope to understand, and explore, important aspects that arise during the knowledge acquisition.

Analysis of research documents: as discussed by Eden and Ackermann (2004), this method can entail ownership issues as experts may not agree with the results of analysis. Moreover, without direct engagement with experts thinking about the future is unusual. The analysis of documents also has narrow focus and it misses subjectivity of expert opinions. As a result, this approach is unlikely to capture expertise and wisdom which reside in the subjective, tacit knowledge (Polanyi 1966b).

Communities of Practice: facilitating the development of Communities of Practice (CoPs) around the topics or risk and resilience in cities could be a good way of sharing expert knowledge about future risk scenarios. However, this approach is demanding in time and resources (Wenger et al. 2002) and it would not be feasible considering the scope of the reported research. This is because CoPs require regular engagement over extended periods of time (Pyrko et al. 2017a). Furthermore, CoPs may not necessarily entail procedural justice (Wenger 1998) - in other words, some voices may become 'silenced' by voices that are more powerful within a community.

Observing or recording knowledge on-the-job: this approach would take an excessive amount of time to cover the breadth of data sought (Orr 1990; Van Maanen 2011). Also, knowledge about future risks scenarios was sought, which is inherently subjective and may not be fully possible to capture 'on-the-job' due to the tacit nature of knowledge obtained from observed experience.

GSS: GSS have been applied for various purposes, such as strategy development with management teams (Paroutis et al. 2015), risk management (Ackermann et al. 2007, 2014; Pyrko et al. 2017b) for brain-storming (Nunamaker et al. 1991), in deci- 
sion making where multiple criteria were a major factor (Lewis 1993; Phillips 2007) and in work with organizations of different sizes and sectors (Ackermann and Eden 2005). GSS have been used extensively to support productive meetings as they provide advantages over traditional meetings such as the ability for all participants to add their contributions at the same time (Ackermann et al. 2016; Valacich et al. 1991) which translates into improved knowledge sharing (Lin 2007).

In a typical GSS-facilitated session, participants from the same organization address a specific set of problems relevant to their work, and by pooling their expertise they cocreate new options to address those problems (Tavella and Franco 2015). The feature of adding contributions at participants' own pace and time was particularly useful to this project, as the participants had not previously known one another. This feature also meant that the GSS enables a large volume of contributions to be obtained in a relatively short amount of time, which helped to address the restrictive availability of the experts. In addition, a GSS can be used to support a process which gathers multiple subjective views, including the context surrounding the knowledge, in a time effective manner. As a result, the complex expert knowledge can be explored in detail, and a wide range of perspectives can be considered. A GSS allows multiple participants to debate their contributions and resolve differences in perspectives and possible conflict. It is still possible that participants 'show off' and try to dominate one another, but this can be tempered by the group process and by appropriate facilitation (Ackermann et al. 2016).

In this project we present a non-traditional approach for using a GSS in a group meeting where experts' views were gathered from participants from multiple organizations with respect to future risk scenarios that a city might face. The following section provides background to the project reported in this paper.

\section{Project Context: "Smart Mature Resilience”}

This paper reports on work undertaken as part of a European-funded research project focusing on developing Smart Mature Resilience $\left(\mathrm{SMR}^{1}\right)$ : making a city more capable of responding to risks, threats, and disasters. The project objective was to develop a new European Resilience Management Guideline that includes five tools which support cities in becoming more resilient. In this paper, we report on the use of a GSS to support the production of one of the five tools called the Risk Systemicity Questionnaire (RSQ). This was to be a decision support tool that aims to support cities in thinking about risks and, in particular, how risks interact with one another to form risk scenarios. The tool was expected to prompt consideration of appropriate mitigation strategies. The RSQ addresses the increasingly recognized need to support today's cities in improving their resilience concerning different kinds of risks (Boin and McConnell 2007; Crichton et al. 2009; Labaka et al. 2015). The development of the RSQ tool draws on previous attempts in the literature to move away from thinking about risks as if they are independent from each other, which is encouraged, for example, when using risk registers (Chapman and Ward 1997; Hull 1990; Mace et al.

1 www.smr-project.eu. 
2015; Patterson and Neailey 2002). The shift of perspective is towards considering how risks and their consequences affect one another: the systemicity of risks (Ackermann et al. 2007, 2014; Williams et al. 1997). Thus, the RSQ supports cities in improving their resilience by learning to appreciate the interactions between risks that they face.

When developing the RSQ, experts were used to gather knowledge about the possible complex ramifications of different risk events that can happen in their cities that create multiple risk scenarios-providing meaning to individual risk events. Expert views were also gathered with respect to the ways in which cities could mitigate these scenarios. Knowledge acquisition was seen as being essential for this project because, as argued by Hardy and Maguire (2016), in order to understand risks one should not only rely on the recording of past events, but instead try to develop insights about the future through conversation and debate among relevant experts. Using a GSS to acquire knowledge is a non-traditional approach and even though participants were highly committed to providing valuable knowledge for the needs of the design of the RSQ tool, the focus was necessarily on fast acquisition of knowledge from experts rather than on 'clients' who expect to benefit immediately from a GSS workshop. This meant there was unlikely to be a sense of ownership of the developing network of risks that merged the knowledge from the multiple experts. Instead, it was only the final tool which the experts would consider using.

In the final two sections of this paper, we consider some of the significant issues and debates associated with gaining expert knowledge when developing a decision support tool, how a GSS can deal these and how they link to the five epistemological challenges described above. We also reflect on some of the trade-offs that are made when using a GSS compared to other methods of knowledge collection. The next section describes how the GSS was used to acquire knowledge to build the decision support tool (the RSQ).

\section{Acquiring Expert Knowledge to Build the Decision Support Tool}

The decision support tool being built aimed to present multiple interconnected risk scenarios to users that addressed many different risk topics. Knowledge acquisition took place during the course of three 1-day workshops, and the collected data were elaborated further in two additional 2-h meetings as well as in eleven test sessions of the constructed tool. There were typically 15 participants in each of the 1-day knowledge acquisition workshops. In total, 25 experts were involved in the workshops (some experts attended multiple workshops). Seven experts were from the UK (Glasgow \& Bristol), 3 from Spain (San Sebastian), 3 from Italy (Rome), 4 from Denmark (Vejle), 4 from Latvia (Riga), 2 from Norway (Kristiansand), 1 from Sweden (Linkoping) and 1 from Germany (Berlin). The cities represented by the experts in the workshop included a range of different types: large/small, on the coast/inland, different governmental contexts, etc. Each participant had expertise in different areas of city resilience including critical infrastructure protection, climate change adaptation, social dynamics, local administration, and European governance and policy-making.

The setting for the workshops is shown in Fig. 1. The participants were chosen by each of the cities following a request that they were either experts or generalists. 


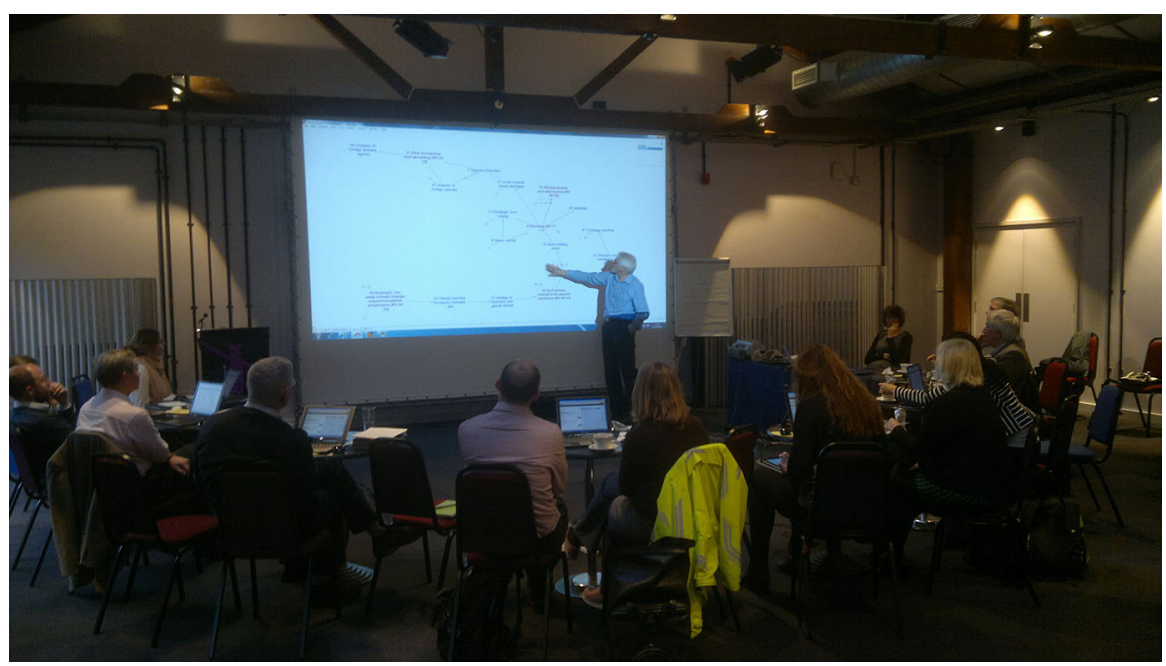

Fig. 1 A Group Explorer workshop

Typically each city sought to send one expert in the three areas being considered (climate change, social dynamics, critical infrastructure) and one generalist. The inclusion of the participants with generalist knowledge ensured that the facilitated discussions were able to focus on how the different types of risks interacted, instead of dwelling on specific detail.

In order to capture systemicity, Group Explorer, ${ }^{2}$ a facilitator guided GSS with a causal mapping facility, was used to explore risk landscapes in cities. Group Explorer addresses the five epistemological challenges of knowledge acquisition described above. Firstly, Group Explorer is a proven approach for engaging experts who had not previously worked together as it helps to encourage them to share knowledge. Group Explorer offers a number of supposed advantages over traditional meetings (Ackermann et al. 2016), such as full anonymity of contributions and ability for all participants to express their views at the same time (rather than only one person talking). Moreover, it enables the presentation of everyone's views in a visual form which can be inspected, compared, and explored during the course of the workshop. This way, causal maps generated with the use of Group Explorer serve its participants as boundary objects and transitional objects. Throughout a Group Explorer session, participants use individual laptops to enter their contributions in the form of short statements or causal links which connect previously added statements on a shared causal map displayed on a large screen. In this research participants worked in seven city pairs or triples, with participants from the same city working together using the same laptop. Group Explorer also enables participants to express their views with

\footnotetext{
2 Group Explorer is a Group Support System (GSS): specially developed software and a networked computer system that facilitates high productivity in collecting multiple perspectives as a group perspective represented as a causal map. The analyses. The system permits establishing the degree of consensus about view, identifying causal loops, and a variety of other supporting software is in the public domain and is open source.
} 


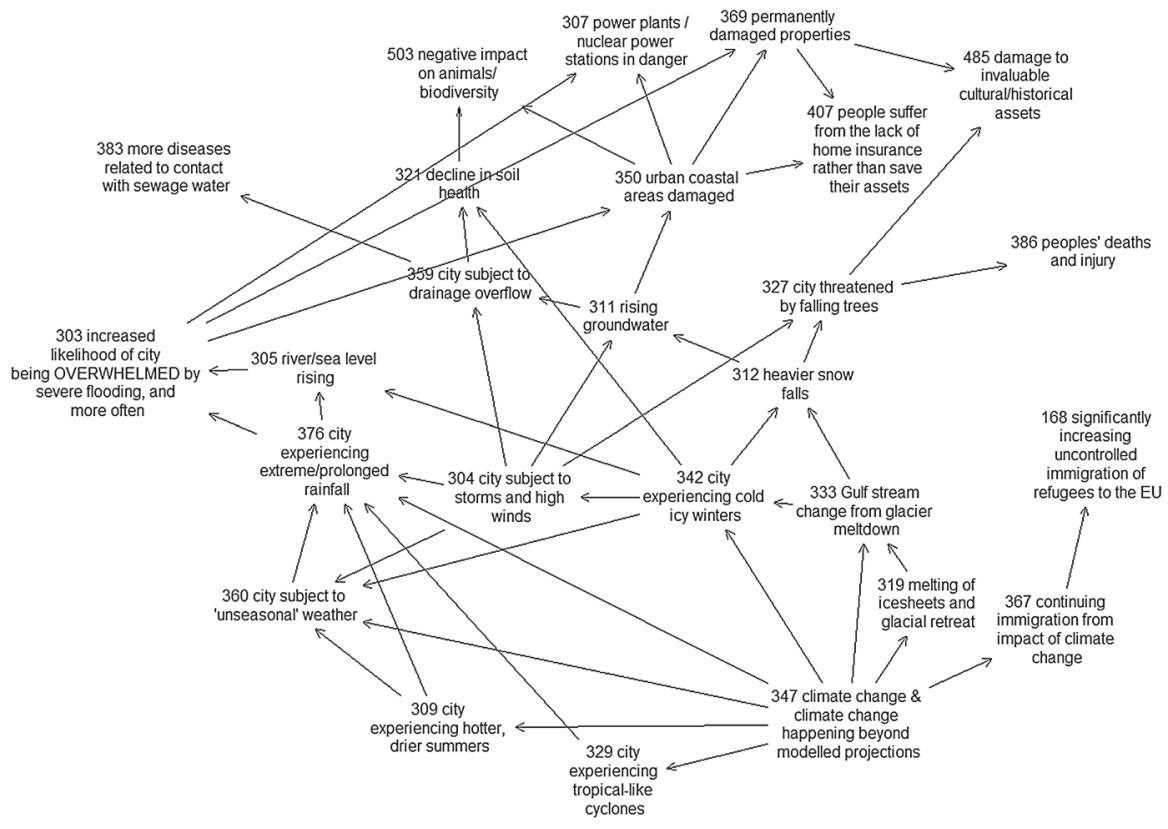

Fig. 2 A segment of a causal map co-created by city participants. *Numbers before statements signify the order in which the statements were added on the map. Links signify 'may lead to' relationships

respect to the significance of statements on the shared causal map by engaging in a voting or rating exercise.

Secondly, Group Explorer allows participants and the facilitator to capture causal relationships between concepts (in this case risks) during the course of a facilitated session using its built-in causal mapping facility (Ackermann and Eden 2005; Ackermann et al. 2005; Paroutis et al. 2015). Each workshop concludes with a tangible outcome-a co-created shared causal map which can subsequently be analyzed. An example of a causal map constructed by city participants in this research is shown in Fig. 2. This figure demonstrates a 'trigger event', statement 347 'climate change happening beyond modelled projections', leading to chains of other risks. A hierarchy of risk outcomes is formed, where some risks are outcomes, while other risks are potent triggers that cause numerous branches of ramifications. Such mapping of risk scenarios captures the context that represents the meaning of the experts' knowledge that surrounds the scenarios. This in turn allows the complexity of knowledge to be explored at both individual and group levels as the individuals' contributions become linked with one another during the session.

Thirdly, the use of Group Explorer enabled considerable results within a limited amount of time. And fourthly, a wide range of perspectives were considered. The software keeps a log of the extent of contributions from each participant and can prompt the facilitator when contributions are uneven. In this paper we particularly concentrate on the three initial workshops during which the empirical material was collected from city participants in a relatively short amount of time. During the sessions 
there was a high level of involvement by all city participants and contributions were relatively even. Thus, the causal maps resulting from each of the three workshops were large and complex. The first 'critical infrastructure' workshop ended with a system of risks that included a network of 183 connected risks (339 causal links), the second 'climate change' workshop ended with 339 risks and 515 links, and the third 'social issues' workshop ended with 427 risks and 764 links. The continuing increase in map complexity was the result of two factors: (1) increasing experience of the participants in using the GSS (more than half of the participants were recurring between the workshops and so they helped new participants to familiarize themselves with using the GSS); and (2) the increasing complexity of the theme.

Fifthly, the process allowed for debate amongst the experts as they sought to resolve conflicting views. This in turn enabled building consensus based on participants' subjective opinions. At various stages of the workshops the facilitator 'paused' the sessions to allow the group to debate and reflect upon the emerging characteristics of the shared causal map. The map in this sense served as a transitional object (de Geus 1988) which changed along with participants' changing minds about the problems in questions (the risks).

Consequently, the use of Group Explorer, a type of GSS, was confirmed as an appropriate method for meeting the five epistemological challenges of knowledge acquisition identified in this paper.

Although this paper focusses on the initial workshops used to gather data, it is important to know how the data that was gathered was then used to develop the decision support tool. The three causal maps resulting from the three data gathering workshops were merged together, reviewed, and tidied after each workshop and the maps were analyzed using established procedures (Bryson et al. 2004). The process of merging involved identifying risks that were similar: the same wording or meaning. In these instances the software enabled two risks to become one risk with all of the associated causation for each of the merged risks to be now associated with the single risk. The tidying of the maps involved editing wording to increase clarity, and adding obvious or well-validated links and statements to complete the existing chains of arguments on the map. The analysis of the data led to the emergence of 10 topics, ${ }^{3}$ each comprising of between 6 and 15 risk scenarios, which formed the basis of the decision support tool. The users of the tool are requested to respond to the likelihood of the scenarios and explore the priorities of those risk scenarios for their city. After users consider each of the risk scenarios, the decision support tool provides a prioritization of risk scenarios to support users in resource allocation. In addition, knowledge about potential mitigation actions was also gathered from participants and is available in the decision support tool for users to consider for those risk scenarios that are of greatest concern to their own cities. The final version of the RSQ was made available both in the Excel and Web-based formats, ${ }^{4}$ and it was implemented in four of the participating European cities as well as being tested by other cities in Europe.

\footnotetext{
3 [1] The 10 risk topics include: elderly population, social cohesion, social alienation, social inequalities, climate change—-flooding, climate change—air pollution, health, community integration, public unrest, and critical infrastructure.

${ }^{4}$ [2] See http://rsq.smr-project.eu/ for a copy of the final RSQ.
} 


\section{Summary: The Use of a GSS and Meeting the Challenges}

We have discussed why a GSS was chosen for knowledge acquisition due to its ability to address the five epistemological challenges raised in Sect. 2, and we have shown how the specific GSS used, Group Explorer, particularly addressed the five challenges. In this section we highlight methodological considerations which emerged during the knowledge acquisition process, how they link to the 5 challenges (shown in bold below) and how the GSS process used above attended to each of them.

The reported research included participants from different countries who were unknown to each other before this work took place and who had not previously participated in this type of GSS session. In the workshops, participants were asked to use their existing knowledge to address a variety of generic risk events (for example 'the city becomes overwhelmed by flooding'). As a result, the researchers had to address a number of methodological considerations which are relevant in this context as opposed to more 'traditional' GSS sessions when working with people from the same organization discussing their own problems.

\subsection{Engaging Participants in a Multiple-Perspective Knowledge Acquisition Session}

As previously mentioned, Group Explorer was used in the project detailed in this paper as it was a proven approach for engaging experts who had not previously worked together. However, once you are able to encourage experts to share knowledge you also need to keep them engaged. Participants had to be kept engaged in discussing risks that may not directly affect their own cities or their own work practice but where, nevertheless, they would have useful experience and knowledge to contribute. Such a situation is in contrast to, for example, strategy workshops where participants hold strong views about the discussed problems (Eden 1992b; Eden and Ackermann 2001). For instance flooding, which was discussed as a risk for cities in the workshops, imposes higher risk for some cities than for other cities. As part of addressing this challenge a review of resilience literature (Malalgoda et al. 2014; Manyena 2006; Taleb 2013) helped to identify a number of resilience-related concepts that could appeal to all participants. Such concepts included, for example, 'bouncing forward' (using the risk events as an opportunity for the organization to learn and to transform itself), or the notion of unintended consequences of cities' responses to risks events (Eusgeld et al. 2011; Rinaldi et al. 2001). The results of the literature review were used to draft the script for the workshops in order to enable everyone's active participation. During the session, the use of relevant technical language and concepts related to resilience helped to establish a common language for the participants, as all participants had a professional interest in resilience. The common language provided a common meaning to the knowledge that was acquired, thus tackling the challenge of subjectivity of knowledge. Moreover, by focusing on the interactions between different kinds of risks expressed through the developed causal maps, cities were able to appreciate how risks which at first may not be relevant to them may impose ramifications for them in the 
long-term. Thus, the developing map linked statements from different participants with different expertise.

\subsection{Acquiring Complex Knowledge in a Short Period of Time}

This methodological consideration relates to the tensions associated with capturing more complexity of knowledge through increasingly complex causal maps versus gaining less knowledge but more understanding from participants. While in more 'traditional' GSS sessions it is usually important to ensure participants build a strong sense of ownership of the content of the causal map, in knowledge acquisition it is more important to gather more knowledge per unit of time. In the workshops, although rigorous preparation allowed the group to work together effectively during the workshops and contribute in a productive manner, at the end of the sessions participants felt limited ownership of the resulting complex map because the co-created content was not tailored to each city's particular circumstances. Thus, as knowledge was being acquired from participants from multiple organizations, the merging of the perspectives led to limited ownership of the resulting map. Another reason that contributed to the lack of ownership was the result of limited organizing/analyzing of the data in the workshop due to the need to gain as much knowledge as possible in a limited period of time. In contrast, in a strategy making or a problem structuring workshop the material is continuously being organized into meaningful chunks. As a result of the limited ownership of the map, it was unlikely that participants would be able to (1) recall and understand the entire content of the maps after the session, (2) appreciate that they contributed to all of the key clusters that were recognized by the group as a whole as being important, (3) 'find their way' through the structure of the maps in a familiar manner, and (4) immediately act upon the outcome of the workshop (Bryson et al. 2004).

\subsection{Structuring the Knowledge Acquisition Workshops}

The next methodological consideration was related to planning the order of a sequence of knowledge acquisition workshops bearing in mind: (1) growing experience of using the GSS, and (2) the relationships between topics, and (3) the expected complexity of knowledge with respect to the topic. Thus the challenge was to work out the sequence in which the different resilience-related topics had to be introduced. When designing GSS workshops for knowledge acquisition it is critical to consider the order in which topics are considered in order to exploit fully the growing experience of using the GSS. The series of workshops need to be planned in advance as a whole rather than as separate sessions, and it is useful to recognize whether different topics for the workshops have distinct levels of difficulty and complexity. Therefore, the workshops are likely to be more productive (e.g. with respect to the number and quality of gathered concepts, and quality of links) when the researchers ensure that those 'less complex' workshops take place first. In this research 'social dynamics' was a more complex and demanding topic for participants than 'critical infrastructure' and 'climate change'. The reason for this was because both climate change and critical infrastructure topics involved 
complex, social dynamics consequences. These consequences could be returned to and discussed during the third workshop that focused on social dynamics. The demanding nature of the social dynamic topic was also evident in the higher complexity of the resulting maps and the 'intangible' nature of this topic. We had not considered how important this factor would be and our appropriate ordering of the topics was the result of serendipity rather than good planning.

\subsection{Validating the Knowledge Acquisition Workshops}

Complexity of knowledge means that when gathering expert knowledge it is important to recognize the context of the knowledge. Group Explorer supported this challenge through capturing the causal relationships between risks. However, in acquisition of vast knowledge, this presents a challenge for researchers/facilitators as they are unlikely to have a good understanding of all of the topics that are being discussed in the workshop due to the expansive content gathered and due to the researchers/facilitators being unlikely to have expertise in all areas being covered. This results in challenges when analyzing and validating resulting models when the researchers cannot draw on a comprehensive understanding of the research topic. The lack of expertise and the large amount of knowledge gathered, means that tidying the map after the session can be a long process. As discussed above, a considerable amount of effort had to be dedicated to tidying the models after the sessions in order to remove duplicate statements, to link the isolated concepts with the rest of the model, and to correct the direction of arrows so that they are made sense 'in the spirit' of the overall style of contributions. Also, the material had to be carefully validated through different means: (1) the three researchers' cross-validation, (2) referring to relevant academic literature and governmental reports, (3) asking city participants to validate parts of the material after the sessions. As a result, the analysis and tidying of the model was laborious and more time consuming than compared to, for example, a strategy workshop. Indeed, in the reported research, the tidying and analysis of the causal maps took a significant amount of the available workload. Furthermore, this challenge is linked closely with the need to balance the group's ownership of the model versus acquiring as much knowledge as possible in relatively little availability of time. Since workshops oriented towards knowledge acquisition place more emphasis on gathering as many links and statements as possible, less work is done on tidying the model with the group and ensuring their ownership of the model.

\section{Discussion and Conclusion}

In this paper we have presented a non-traditional application of GSS in which the aim was to acquire vast expert knowledge in a short amount of time. Such application of GSS imposed a number of epistemological and methodological challenges which have been explored carefully, aiming to build the ground for future research and practice. Overall, the products of the workshop enabled the design of what is regarded by the cities as an effective and useful decision support tool, and the co-created risk 
systemicity scenarios embedded in the tool have been received enthusiastically by the cities as they found them insightful. In this section, on the basis of our experiences in this project, we consider key factors in successfully using a GSS for knowledge acquisition.

Although knowledge acquisition with the seven cities was considered successful, researchers intending to conduct projects of a similar nature are advised to appreciate the demands which such projects can impose on them. Firstly, due to the various methodological considerations discussed above, the GSS sessions were particularly demanding on the part of facilitators (this was mitigated by the fact that the lead facilitator had substantial experience in the practice of GSS facilitation), and so the GSS sessions required careful preparation of the script in advance of the session.

As part of the workshop preparation, where there are a series of consecutive meetings, it is essential to plan the scripts of the sessions in a way that the topics allow for incremental increases in the complexity of discussions so that the participants can conveniently build on the material contributed in the preceding sessions. In other words, in knowledge acquisition the incremental complexity should be explicitly considered when planning the research design, whereas, for example, in strategy workshops the increasing complexity can emerge more organically. Secondly, when working with participants who are from different organizations and who are facing different issues or do not have a shared stake in the discussed problems, it is essential to find a structure for the session that will be attractive to all participants. In this research a rigorous exploration of the subject literature helped to overcome the difficulties associated with the researchers' limited understanding of the participants' particular work context and to establish the ground for common understanding between participants. And thirdly, due to the fact that in knowledge acquisition sessions less work is done by the group of participants to tidy the map 'on the hoof' and develop a shared ownership of the model, researchers need to be prepared to invest a large amount of time on the analysis of the gathered data following the workshops.

Whereas knowledge acquisition using GSS can be seen as a challenging endeavor, especially when working with a diverse group of participants, it can be a good way of acquiring vast knowledge in a relatively short period of time. Further refinement of the approach discussed in this paper is therefore a promising direction for future research. In a complex, changing world the ability to integrate the knowledge of different experts can be considered particularly important as a way of developing and creating new knowledge (Davenport 2005; Pyrko et al. 2017a), and an informed use of a GSS can be a good way of enabling such valuable group collaboration.

This paper operationalizes the practical responses to the epistemological challenges involved in knowledge acquisition, which is not an unproblematic process. With the aid of GSS, sharing of tacit knowledge was facilitated and participants had an expectation of learning from their involvement with other experts. Some elements of participants' tacit knowledge were externalized, however we note that tacit knowledge, of course, is unlikely to be fully converted into explicit form (Tsoukas 2005). The complexity of expert knowledge was managed, and explored, through elaboration of a shared causal map co-created by the participants. Thus participants were drawing on the co-produced causal maps, which helped to contextualize their knowledge, and so enabled learning from one another. As a result, while the production of a causal map could be seen 
an imperfect knowledge externalization, the very process of social production of the maps gave participants opportunities for 'thinking together' (Pyrko et al. 2017a) and so sharing deep, tacit knowledge indirectly. The time demands restricted by the experts' availability were addressed by employing a highly efficient and productive facilitation process which translated into a large amount of gathered empirical material. The risk scenarios, which were the focus of the sessions, were investigated from multiple perspectives, and they entailed merging the contributions from across different risk themes. Participants were also particularly conscious that presenting their views about the future represented high degrees of subjectivity - they recognized that it was not always possible to project the past into the future and so were equivocal about their own levels of confidence about a point of view. Thus, while appreciating the challenge of acquiring vast expert knowledge to learn about future risk scenarios, we argue that use of a GSS can be a good approach for learning about the future by listening to the experts' collective wisdom.

As we reflect on the overall efficacy of using a GSS rather than any of the other four methods we noted in Sect. 3, we identify three key trade-offs that are made when using a GSS. Firstly, the analysis of published research documents would probably have undoubtedly led to more verifiable knowledge about risks and their interactions. As we analyzed the data collected through GSS workshops we were conscious of some highly questionable assertions for which we could find no support in any documents. We had to use the analysis of documents to explore the validity of many risk scenarios. We suspect we could have gained 'deeper knowledge' from the analysis of documents. However, conversely we would have lost many other important outcomes: expert intuition, reaction and debate among experts, wider interconnection between topics (where documents tend to be highly focused), and practical knowledge based on real experiences. In part, this raised an issue about 'who are the experts'? Most well researched knowledge is published by academic researchers not practitioners. Secondly, although the speed of knowledge acquisition was outstanding, where the outcome at the end of a GSS workshop was a first draft of the complex knowledge of the experts, the amount of data and the rate of acquisition probably came at the cost of too little time to reflect on it. Finally, there is an interesting cost equation: the cost of experts versus the cost of analysts. Our GSS workshops involved about 20 persondays of expert time whereas the cost of interviews would likely have been about 5 person-days but with significantly higher analyst costs. The GSS workshop involves additional time allowing for debate and merging of contributions which the analyst would need to replace when dealing with material from interviews. The experience of this project suggests that the gains of using a GSS easily justify the additional cost of expert time.

In conclusion, this paper contributes to the GSS literature by (1) presenting the epistemological challenges of using a GSS for knowledge acquisition and (2) outlining the key methodological challenges which are specific to this particular application of GSS and how they can be addressed. In such sense our work extends the current GSS literature (Ackermann and Eden 2005; Ackermann et al. 2005; Lewis 2010; Liou and Nunamaker 1990) which does not elaborate on these challenges in relation to knowledge acquisition. Our contribution has highlighting three key trade-offs which occur when using a GSS as compared to other methods of knowledge acquisi- 
tion. The epistemological challenges addressed in this paper may also appeal to the wider management readership as they offer a practical perspective on the possibilities and limitations which are entailed by knowledge acquisition in organizations. Future research may explore this method in different settings and contexts, for example in the private sector or when working with a single organization. This method could also be elaborated as a business-oriented process for gathering knowledge about commercial problems and strategic or operational issues that requires efficient outcomes when the time available is scarce.

Acknowledgements The research reported in this paper was conducted as part of the Smart Mature Resilience project which is funded by the European Union's Horizon 2020 Program (H2020-EU.3.7., Project Ref. 653569). The project commenced on 1st June 2015 and finished on 30th June 2018.

Open Access This article is distributed under the terms of the Creative Commons Attribution 4.0 International License (http://creativecommons.org/licenses/by/4.0/), which permits unrestricted use, distribution, and reproduction in any medium, provided you give appropriate credit to the original author(s) and the source, provide a link to the Creative Commons license, and indicate if changes were made.

\section{References}

Ackermann F, Eden C (2005) Using causal mapping with group support systems to elicit an understanding of failure in complex projects: some implications for organizational research. Group Decis Negot 14:355-376. https://doi.org/10.1007/s10726-005-8917-6

Ackermann F, Eden C (2011) Strategic management of stakeholders: theory and practice. Long Range Plan 44:179-196. https://doi.org/10.1016/j.lrp.2010.08.001

Ackermann F, Franco LA, Gallupe B, Parent M (2005) GSS for multi-organizational collaboration: reflections on process and content. Group Decis Negot 14:307-331. https://doi.org/10.1007/s10726-0050317-4

Ackermann F, Eden C, Williams T, Howick S (2007) Systemic risk assessment: a case study. J Oper Res Soc 58:39-51. https://doi.org/10.1057/palgrave.jors.2602105

Ackermann F, Howick S, Quigley J, Walls L, Houghton T (2014) Systemic risk elicitation: using causal maps to engage stakeholders and build a comprehensive view of risks. Eur J Oper Res 238:290-299. https://doi.org/10.1016/j.ejor.2014.03.035

Ackermann F, Eden C, Pyrko I (2016) Accelerated multi-organization conflict resolution. Group Decis Negot 25:901-922. https://doi.org/10.1007/s10726-016-9472-Z

Alvesson M (2011) Interpreting interviews. SAGE, London

Barney J (1991) Firm resources and sustained competitive advantage. J Manag 17:99-120. https://doi.org/ $10.1177 / 014920639101700108$

Boin A, McConnell A (2007) Preparing for critical infrastructure breakdowns: the limits of crisis management and the need for resilience. J Conting Crisis Manag 15:50-59. https://doi.org/10.1111/j.14685973.2007.00504.x

Borzillo S, Kaminska-Labbé R (2011) Step-in or step-out: supporting innovation through communities of practice. J Bus Strategy 32:29-36. https://doi.org/10.1108/02756661111121974

Borzillo S, Schmitt A, Antino M (2012) Communities of practice: keeping the company agile. Journal of Business Strategy 33:22-30

Brown JS, Duguid P (2000) Social life of information. Harvard Business Press, Boston

Bryson JM, Ackermann F, Eden C, Finn CB (2004) Visible thinking — unlocking causal mapping for practical results. Wiley, Chichester

Carlile PR (2002) A pragmatic view of knowledge and boundaries: boundary objects in new product development. Organ Sci 13:442-455. https://doi.org/10.1287/orsc.13.4.442.2953

Carlile PR (2004) Transferring, translating, and transforming: an integrative framework for managing knowledge across boundaries. Organ Sci 15:555-568. https://doi.org/10.1287/orsc.1040.0094

Chapman C, Ward S (1997) Project risk management: processes, techniques and insights. Wiley, Chichester 
Crichton MT, Ramsay CG, Kelly T (2009) Enhancing organizational resilience through emergency planning: learnings from cross-sectoral lessons. J Conting Crisis Manag 17:24-37. https://doi.org/10.1111/j. 1468-5973.2009.00556.x

Davenport TH (2005) Thinking for a living. How to get better performance and results from knowledge workers. Harvard Business Press, Boston

Davenport TH, Prusak L (2000) Working knowledge. How organizations manage what they know. Harvard Business School Press, Boston

de Geus A (1988) Planning as learning. Harv Bus Rev March/April:70-74

Donate MJ, Canales JI (2012) A new approach to the concept of knowledge strategy. J Knowl Manag 16:22-44. https://doi.org/10.1108/13673271211198927

Dörfler V (2010) Learning capability: the effect of existing knowledge on learning. Knowl Manag Res Pract 8:369-379. https://doi.org/10.1057/kmrp.2010.15

Drucker PF, Maciariello JA (2008) management. HarperCollins, New York

Dundon T, Ryan P (2010) Interviewing reluctant respondents: strikes, henchmen, and gaelic games. Organ Res Methods 13:562-581. https://doi.org/10.1177/1094428109335571

Easterby-Smith M, Thorpe R, Jackson RP (2015) Management and business research, 5th edn. Sage, London

Eden C (1992a) One the nature of cognitive maps. J Manag Stud 29:261-265. https://doi.org/10.1111/j. 1467-6486.1992.tb00664.x

Eden C (1992b) Strategy development as a social process. J Manag Stud 29:799-812. https://doi.org/10. 1111/j.1467-6486.1992.tb00690.x

Eden C (2004) Analyzing cognitive maps to help structure issues or problems. Eur J Oper Res 159:673-686. https://doi.org/10.1016/S0377-2217(03)00431-4

Eden C, Ackermann F (2000) Mapping distinctive competencies: a systemic approach. J Oper Res Soc 51:12-20. https://doi.org/10.2307/253943

Eden C, Ackermann F (2001) Group decision and negotiation in strategy making. Group Decis Negot 10:119-140. https://doi.org/10.1023/a:1008710816126

Eden C, Ackermann F (2004) Cognitive mapping expert views for policy analysis in the public sector. Eur J Oper Res 152:615-630. https://doi.org/10.1016/S0377-2217(03)00061-4

Eden C, Jones S, Sims D, Smithin T (1981) The intersubjectivity of issues and issues of intersubjectivity. J Manag Stud 18:37-47. https://doi.org/10.1111/j.1467-6486.1981.tb00090.x

Eden C, Pyrko I, Howick S (2017) Knowledge acquistion using group support systems. In: Mareike SD, Kilgour MD (eds) 17th international conference GDN Stuttgart, Germany, August 14-18, 2017. Springer

Eusgeld I, Nan C, Dietz S (2011) "System-of-systems" approach for interdependent critical infrastructures. Reliab Eng Syst Saf 96:679-686. https://doi.org/10.1016/j.ress.2010.12.010

Gherardi S (2000) Practice-based theorizing on learning and knowing in organizations. Organization 7:211-223. https://doi.org/10.1177/135050840072001

Handy C (1995) The age of unreason. Arrow Books Ltd, London

Handy C (2016) The second curve: thoughts on reinventing society. Random House Business, London

Hardy C, Maguire S (2016) Organizing risk: discourse, power, and "riskification". Acad Manag Rev 41:80-108. https://doi.org/10.5465/amr.2013.0106

Hull JK (1990) Application of risk analysis techniques in proposal assessment. Int J Proj Manag 8:152-157. https://doi.org/10.1016/0263-7863(90)90016-5

Kelly G (1955) The psychology of personal constructs. Norton, New York

Labaka L, Hernantes J, Sarriegi JM (2015) Resilience framework for critical infrastructures: an empirical study in a nuclear plant. Reliab Eng Syst Saf 141:92-105. https://doi.org/10.1016/j.ress.2015.03.009

Lewis F (1993) Decision-aiding software for group decision making. In: Nagel S (ed) Computer-aided decision analysis: theory and applications. Quorum Books, Westport

Lewis F (2010) Group support systems: overview and guided tour. In: Kilgour DM, Eden C (eds) Handbook of group decision and negotiation. Springer, Dordrecht, pp 249-268

Lin H-F (2007) Effects of extrinsic and intrinsic motivation on employee knowledge sharing intentions. J Inf Sci 33:135-149. https://doi.org/10.1177/0165551506068174

Lindkvist L (2005) Knowledge communities and knowledge collectivities: a typology of knowledge work in groups*. J Manag Stud 42:1189-1210. https://doi.org/10.1111/j.1467-6486.2005.00538.x

Liou YI, Nunamaker JF (1990) Using a group decision support system environment for knowledge acquisition: a field study. In: Twenty-third annual Hawaii international conference on system sciences, 2-5 Jan. 1990. vol 43, pp 40-49. https://doi.org/10.1109/hicss.1990.205326 
Mace GM, Hails RS, Cryle P, Harlow J, Clarke SJ (2015) REVIEW: towards a risk register for natural capital. J Appl Ecol 52:641-653. https://doi.org/10.1111/1365-2664.12431

Malalgoda C, Amaratunga D, Haigh R (2014) Challenges in creating a disaster resilient built environment. Procedia Econ Finance 18:736-744. https://doi.org/10.1016/S2212-5671(14)00997-6

Manyena SB (2006) The concept of resilience revisited. Disasters 30:434-450. https://doi.org/10.1111/j. 0361-3666.2006.00331.x

McDermott R (1999) Why information technology inspired but cannot deliver knowledge management. Calif Manag Rev 41:103-117

McDermott R, Archibald D (2010) Harnessing your staff's informal networks. Harv Bus Rev 88:82-88

Nonaka I, Takeuchi H (1995) The knowledge-creating company: how japanese companies create the dynamics of innovation. Oxford University Press, New York

Nunamaker JF, Dennis AR, Valacich JS, Vogel DR (1991) Information technology for negotiating groups: generating options for mutual gain. Manag Sci 37:1325-1346. https://doi.org/10.2307/2632403

Orr JE (1990) Sharing knowledge, celebrating identity: community memory in a service culture. In: Middleton D (ed) Collective remembering inquiries in social construction. Sage Publications, London

Paroutis S, Franco LA, Papadopoulos T (2015) Visual interactions with strategy tools: producing strategic knowledge in workshops. Br J Manag 26:S48-S66. https://doi.org/10.1111/1467-8551.12081

Patterson FD, Neailey K (2002) A risk register database system to aid the management of project risk. Int J Proj Manag 20:365-374. https://doi.org/10.1016/S0263-7863(01)00040-0

Phillips L (2007) Decision conferencing. In: Edwards W, Miles RF Jr, von Winterfeldt D (eds) Advances in decision analysis: from foundations to applications. Cambridge University Press, New York, pp 375-399

Polanyi M (1962) Personal knowledge. The University of Chicago Press, Chicago

Polanyi M (1966a) The logic of tacit inference. Philosophy 41:1-18

Polanyi M (1966b) The tacit dimension reissue. University of Chicago Press, Chicago

Polanyi M (1967) Sense-giving and sense-reading. Philosophy 42:301-325. https://doi.org/10.2307/ 3748494

Pyrko I, Dörfler V, Eden C (2017a) Thinking together: What makes communities of practice work? Hum Relat 70:389-409. https://doi.org/10.1177/0018726716661040

Pyrko I, Howick S, Eden C (2017b) Risk systemicity and city resilience. Paper presented at the EURAM conference, Glasgow, UK, 21--24.06.2017

Rinaldi SM, Peerenboom JP, Kelly TK (2001) Identifying, understanding, and analyzing critical infrastructure interdependencies. IEEE Control Syst 21:11-25. https://doi.org/10.1109/37.969131

Roberts J (2006) Limits to communities of practice. J Manag Stud 43:623-639. https://doi.org/10.1111/j. 1467-6486.2006.00618.x

Shaw D, Smith CM, Scully J (2017) Why did Brexit happen? Using causal mapping to analyse secondary, longitudinal data. Eur J Oper Res 263:1019-1032. https://doi.org/10.1016/j.ejor.2017.05.051

Snowden D (2003) Innovation as an objective of knowledge management. Part I: the landscape of management. Knowl Manag Res Pract 1:113-119

Spender JC (1996) Organizational knowledge, learning and memory: three concepts in search of a theory. J Organ Change Manag 9:63-78

Starbuck WH (1992) Learning by knowledge-intensive firms. J Manag Stud 29:713-740. https://doi.org/ 10.1111/j.1467-6486.1992.tb00686.x

Taleb NN (2013) Antifragile: things that gain from disorder. Penguin, London

Tavella E, Franco LA (2015) Dynamics of group knowledge production in facilitated modelling workshops: an exploratory study. Group Decis Negot 24:451-475. https://doi.org/10.1007/s10726-014-9398-2

Thompson M, Walsham G (2004) Placing knowledge management in context. J Manag Stud 41:725-747

Tsoukas H (1996) The firm as a distributed knowledge system: a constructionist approach. Strateg Manag J 17:11-25. https://doi.org/10.2307/2486988

Tsoukas H (2005) Do we really understand tacit knowledge? In: Tsoukas H (ed) Complex knowledge: studies in organizational epistemology. Oxford University Press, New York, pp 141-161

Tsoukas H, Vladimirou E (2001) What is organizational knowledge? J Manag Stud 38:973-993. https:// doi.org/10.1111/1467-6486.00268

Valacich JS, Dennis AR, Nunamaker JF (1991) Electronic meeting support: the GroupSystems concept. Int J Man Mach Stud 34:261-282. https://doi.org/10.1016/0020-7373(91)90044-8

Van Maanen J (2011) Tales of the field: on writing ethnography, 2nd edn. University of Chicago Press, Chicago 
Walz DB, Elam JJ, Curtis B (1993) Inside a software design team: knowledge acquisition, sharing, and integration. Commun ACM 36:63-77. https://doi.org/10.1145/163430.163447

Wenger E (1998) Communities of practice: learning, meaning and identity. Cambridge University Press, Cambridge

Wenger E (2000) Communities of practice: the key to knowledge strategy. In: Lesser EL, Fontaine MA, Slusher JA (eds) Knowledge and communities. Butterworth-Heinemann, Woburn

Wenger E, Snyder W (2000) Communities of practice: the organizational frontier. Harv Bus Rev January/February:139-145

Wenger E, McDermott R, Snyder WM (2002) Cultivating communities od practice. Harvard Business School Press, Boston

Wickert A, Herschel R (2001) Knowledge-management issues for smaller businesses. J Knowl Manag 5:329-337. https://doi.org/10.1108/13673270110411751

Williams T, Ackermann F, Eden C (1997) Project risk: systemicity, cause mapping and a scenario approach. In: Kahkonen K, Artto K (eds) Managing risks in projects. E\&FN Spon, London, pp 343-352

Publisher's Note Springer Nature remains neutral with regard to jurisdictional claims in published maps and institutional affiliations. 